\title{
Effect of Educational Nursing Program on Nurses' Awareness About Cervical Cancer at Assiut Women's Health Hospital
}

\author{
Amal Fouad Arief \& Entisar Younes Mohamed. \\ Lecturer of Obstetrics \& Gynecological Nursing, Faculty of Nursing, Assiut University Egypt. \\ Assistant professor of Obstetrics \& Gynecological Nursing, Faculty of Nursing, Assiut University Egypt.
}

\begin{abstract}
Background: Worldwide, cervical cancer is the third most common type of cancer in women, it is claims the life of almost half a million women worldwide each year. Aim: To assess the effect of educational program on nurse's awareness about cervical cancer. Subject and method: A quiz experimental study design was used in this study, the sample included all nurses working in the Assiut Women's Health Hospital, they were 66 nurse. Pre and post test done to evaluate nurse's awareness about cervical cancer based on evaluation of nurses knowledge and attitude about cervical cancer .Results: The majority of the sample lived in rural area and had a diploma degree in nursing. The mean age of nurses were 29.3 \pm 9 .6year, near to three-quarter of nurses had adequate knowledge about cervical cancer and more than two-thirds of them had positive attitude toward Pap smear as a screening test after implementation of the educational program, also it was observed a statistical significant relation for nurse's knowledge in pre and post test. Conclusion: There was an improvement in nurses' level of knowledge and their attitude become positive toward cervical cancer screening. Recommendations: Provide educational program about cervical cancer and its preventive measurements for nurse in all areas that provide maternity services.
\end{abstract}

\section{Keywards: Cervical Cancer, Screening Test, Pap Smear \& Nurses Knowledge.}

\section{Introduction}

Cervical Cancer (CC) is the second most common cancer among women with early detection and prompt treatment as best management options Arulogun \& Maxwel (2012), The highest incidence rates of cervical cancer have been reported from subSaharan Africa, Central and South America AlShaikh et al., (2014).

It is estimated that over than one million women worldwide currently have cervical cancer (Arulogun \& Maxwell, 2012); Cervical cancer is the third most common cancer in the world, with 2.3 million prevalent cases and 510, 000 incident cases each year. Annually, 288000 women die of cervical cancer and $80 \%$ of these deaths occur in low- resource countries (Abdul-Aziz 2012). About $86 \%$ of the cases occur in developing countries, representing 13\% of female cancers (Goyal et al., 2013).

Egypt has a population of 30.55 million women ages 15 years and older who are at risk of developing cervical cancer. Current estimates indicated that every year 866 women are diagnosed with cervical cancer and 373 die from the disease. Cervical cancer ranks as the 13th most frequent cancer among women in Egypt and the 10th most frequent cancer among women between 15 and 44 years of age (ICO Information Centre on HPV \& Cancer, 2015). Despite being a preventable disease, cervical cancer claims the life of almost half a million women worldwide each year. India bears one-fifth of the global burden of the disease, with approximately 130,000 new cases every year (Shekhar et al., 2013), the burden and impact of the disease remains high in the developing countries, with an average annual increase of $0.6 \%$; about $85 \%$ of its burden occurs in the developing countries, where it accounts for $13 \%$ of all cancers in women (Gan \& Dahlui, 2013).

One of the widely used screening tests in the early detection of precancerous lesions and cervical cancer cells is the Papanicolaou test or the Pap smear test (Sandy, 2010). Pap smear or cervical smear-detects abnormal cells in a sample taken from the cervix. It involves performing a speculum examination to expose the cervix and collecting cervical cells using a wooden or plastic spatula, broom, or brush (WHO, 2004).

Cervical cancer is a unique cancer as it is known to have a long pre-invasive stage (10 years or more), Papanicolaou cytological testing (Pap smear) permits cervical lesions to be detected before they become cancerous, it is effectively reducing the incidence of cervical cancer by 75\%-90\% (Al-Meer et al., 2011). The recorded decrease in the incidence and mortalities of $70-80 \%$ of cervical cancer in western countries \& in developed nations is largely due to widespread screening and performing Pap smear (Sandy, 2010, Thippeveeranna et al., 2013).

Despite the effectiveness of screening programs such as Pap smear in preventing the cervical cancer, high incidence and high mortality of cervical cancer has 
continued because attitudes and beliefs towards the test are negative (Sandy, 2010) In the developing nations opportunistic screening is the practice, and many women present with late-stage disease (Goyal et al., 2013).

Women's knowledge of cervical cancer is very limited. It has been demonstrated that vast majority of women in some African countries had not heard of cervical cancer and even more knew nothing about cervical screening (Al-Meer et, al. 2011).

Nurses have a responsibility not only for improvement of public health but also improvement of their own health. In order to improve early detection in the general population, it is very important that health workers (physicians, nurse, and midwife) be able to recognize the major risk factors relevant to the development of cancer (Ertem \& A Kocer, 2009). Nurses and midwives are ideal health professionals' persons who can increase public knowledge about cervical cancer (Arulogun \& Maxwell, 2012)

Health workers especially nurses are often times looked upon as "role models" in health related issues. Nurses play a major role in enlightening the public on the availability and need for cervical cancer screening services (Arulogun \& Maxwell, 2012). Nurses, who form a major part of health workers, often, give health talks in clinics and interact with patients and their relations; they can now play a crucial role in women's education about cervical cancer screening methods (Adenike, et al., 2010).

\section{Significant of the study}

Fouda \& Elkazeh (2013) reported that the incidence of cervical cancer in Egypt by cancer registry is 2.1 per 100,000 women per year. This condition affects not only the health and lives of the women but also their children, families and their communities at large. The number of cancer patients in Egypt is expected to expand in the future as the population continues to grow and age, as well as the prevalence of known etiological factors, increase (A Qalawa et al., 2013)

Health team who is responsible for screening women is not keen on getting their selves screened. Negative practices and beliefs towards Pap smear can be possibly corrected through proper education and understanding that this method can significantly reduces the occurrence of cervical cancer.

This study deals with the level of knowledge about Pap smear and its importance in the early detection and treatment of cervical cancer among staff nurses, and thus being beneficial in the evaluation of the effectiveness of their information dissemination with regards to the importance of regular Pap smear and its role in the early detection of cervical cancer. The outcome of this study determined the necessity for a more intense information spread.

This study also is being beneficial in ensuring that the staff nurses are providing the right information regarding Pap smear and its importance in the early detection and treatment of cervical cancer to female clients at reproductive age. This study provides correctness and sufficiency of the staff nurses' knowledge. So, researches can see the importance of assessing the nurse's awareness about Pap smear to diagnoses of cervical cancer at Assiut University Hospital.

\section{Aim of the study \\ This study aimed to}

Assess the effect of educational program on nurse's awareness about cervical cancer.

\section{Research Hypothesis}

Implementing the educational nurses program about cervical cancer and its screening test will improve nurse's knowledge and attitude toward it.

\section{Subject \& methods Research design}

A quasi-experimental study design was used in this study.

Setting:

The study took place at the Women's Health Hospital- Assiut University. This hospital provides free services for women from Assiut governorate and other neighboring governorates.

\section{Sample}

Convenient sample included all nurses that working in the Women's Health Hospital, who agreed to participate in the study and enrolled in the work.

All nurses who work at the Women's Health Hospital at the gynecological department which included inpatient unit, outpatient clinic and operating room for gynecological operation, the total number of the nurses 109 nurse, 27 of these dose not on duty and 5 nurses refused to participate in the study and 11 nurses included in the pilot study and was excluded from the total study sample, so the total nurses number recruited in the study were 66 nurse.

\section{Tools for data collection}

A structure self-administrative questionnaire was developed by the researchers in simple Arabic language based on a review of current and previous national and international literatures and journals to assess the nurses knowledge and attitude toward cervical cancer.

The structured self-administrative questionnaire included three parts as the following: 
Part (1):

- Socio-demographic data: which included: age, marital status, residency, educational level, and years of experience.

- Obstetrical history: which Included: number of pregnancies, deliveries, and number of abortions.

Part (2): which include questions to assess the nurse's knowledge about cervical cancer as

Cervical cancer symptoms, causes, risk factors, whither it is sexually transmitted or not and its preventive methods. It's including also definition of Pap smear, the schedule of Pap smear screening test; it's time and its follow-up schedule, its possible results. 24 questions to assess nurses' knowledge about cervical cancer symptoms (12 questions) and risk factors, 6 questions to assess knowledge about Pap. smear screening test, each question was given a score of zero to maximum of 1 , with a total score of 24 marks.

\section{Scoring system}

The total score of knowledge was 24 marks. Each correct answer was given one mark and the incorrect and don't know answers were given zero. It was categorized as follows:

score of $60 \%$ was considered satisfactory level of knowledge and score of $\quad<60 \%$ was considered unsatisfactory level of knowledge.

Part (3): Nurses awareness toward cervical cancer screening test

It included questions to assess the nurses attitude toward cervical cancer and its screening test as; whither she was at risk or not for cervical cancer, perform Pap smear or not and causes for performing Pap smear, discuss cervical cancer screening with their relatives or not. 3 points likert scale used to assess the nurses attitude, it contain three responses as 1) strongly agree, 2) agree,3)not agree.

Attitude scoring system

Nurse's attitude considered positive if she had a score of $60 \%$ and negative attitude if the total score was less than $60 \%$.

\section{Administrative design}

It included the preparatory phase, pilot study, and field work.

\section{Preparatory phase}

Researchers reviewed related literatures of the current study, local and international; using text books articles and specialized journals to prepare the tool of data collection, then tool was tested for validity by experts in obstetrics and gynecological staff Faculty of Nursing \& Faculty of Medicine.

Pilot study: $10 \%$ of the nurses (11 nurses) were recruited at the pilot study to explore the celerity, feasibility and easiness of the questionnaire, also to determine the needed time for data collection and probable time for teaching the program contents. The necessary modification was done accordingly; the nurses who were included in the pilot study were excluded from the sample size.

Procedure (field work)

An official letter of approval of the study was obtained from the Dean of the Women Health Hospital- Assiut University Hospital and from Dean the faculty of Nursing Assiut University, the letter include the aim and nature of the study.

An oral consent was taken from each nurse after full explanation of the program; the nature and the study aim, nurses were informed that the information taken for only the research purpose and confidentiality was obtained and the nurse have the right to withdrawn from the study at any time.

\section{The study took place through two phases:}

Phase one

-All nurses were interviewed at the end of morning shift, divided into section. Every one contained from 3-5 nurses, after explanation the nature and aim of the study. They were interviewed at their work sitting (gynecological outpatient's clinic, inpatient's word etc...........)

- Nurses were informed that the collected data was only for research reasons and she can refuse to participate in the study or withdrawn at any time, this interview tooked about 15-20 mints.

- Pretest questionnaire was collected which included knowledge about cervical cancer, Pap smear, and attitude as regard cervical cancer screening.

- The nurse given information about cervical cancer, its nature, causes, symptoms and preventive methods. The Pap smear also explained to the nurse, its nature, the proper time, schedule of follow-up, and its possible results

- Nurse's role as a health model in the hospital and community and a care giver also discussed to encourage nurses to discuss the cervical cancer prevention with their families and relatives.

- The nurse were informed about the second meeting which took place after 3 months to assess their knowledge about cervical cancer and Pap smear, and whither she did a Pap smear or not for her won, their phone numbers were taken to remind them about the time of the second interview.

\section{Phase two}

- After three months the second interview was occurred after phone calling to ask every nurse about the suitable time to attend the interview.

- the nurse was interviewed at the end of the morning shift where the post test evaluation took place by evaluating the nurses' knowledge about cervical cancer screening, its symptoms, causes, and prevention, Pap smear, and attitude as regard cervical cancer screening 
- The nurse also asked about Pap smear, its time, follow-up schedule, possible results. The nurse also asked about Pap smear whither she perform it for herself within three months period or not and explain it to their relatives or not.

- The researcher collected the data over three month's period, through two days every week; the study was carried in the period from April 2016 through Jun 2016.

Statistical analysis

The data was tested for normality using the AndrsonDarling test for homogenicity variance prior to further statistical analysis. Categorical variables were described by number and percentage, where continues variables described by mean and statistical deriation (mean \& SD). Chi-square test \& Fisherexact test used to compeer between categoral variables \& t-test used to compeer between continuous variables. A two- tailed $\mathrm{P} \leq 0.05$ was considered statistically significant. All analysis was done by using the IBM SPSS (20) software.

\section{Results}

Table (1) Distribution of the studied nurses according to their sociodemographic characteristics.

\begin{tabular}{|c|c|c|}
\hline & No. $=66$ & $\%$ \\
\hline \multicolumn{3}{|l|}{ Nurse's age } \\
\hline 20-25 years. & 38 & 57.6 \\
\hline 26-30 years. & 5 & 7.6 \\
\hline 31-35 years. & 6 & 9 \\
\hline More than 35 years & 17 & 25.8 \\
\hline Mean age/ year & \multicolumn{2}{|c|}{$29.3 \pm 9.6$} \\
\hline \multicolumn{3}{|l|}{ Residence: } \\
\hline Urban & 44 & 66.7 \\
\hline Rural & 22 & 33.3 \\
\hline \multicolumn{3}{|l|}{ Marital status } \\
\hline Single & 23 & 34.8 \\
\hline Married & 43 & 65.2 \\
\hline \multicolumn{3}{|l|}{ Qualifications of nurses } \\
\hline Diploma of nursing & 39 & 59.1 \\
\hline Bachelor of nursing & 11 & 16.7 \\
\hline Technical institution of nursing & 16 & 24.2 \\
\hline \multicolumn{3}{|l|}{ Duration of work } \\
\hline Range/ year & \multicolumn{2}{|c|}{$0-40$} \\
\hline Mean \pm SD years. & \multicolumn{2}{|c|}{$10.0 \pm 9.6$} \\
\hline \multicolumn{3}{|l|}{ Place of work } \\
\hline Laparoscopy unit & 5 & 7.6 \\
\hline Operating room & 14 & 21.2 \\
\hline In patient department(obstetrical \&diagnosis) & 45 & 68.2 \\
\hline Out patient's clinic. & 2 & 3.0 \\
\hline \multicolumn{3}{|l|}{ Years of experience } \\
\hline Less than 5 years & 25 & 37.9 \\
\hline $5-10$ years & 18 & 27.3 \\
\hline More than 10 years & 23 & 34.8 \\
\hline
\end{tabular}


Table (2): Distribution of the studied nurses according to their obstetrical history.

\begin{tabular}{|l|c|c|}
\hline & \multicolumn{2}{|c|}{ No.=66 } \\
\hline Number of deliveries & \multicolumn{2}{|c|}{} \\
\hline Nulli- Para & 26 & 39.4 \\
\hline Multipara & 31 & 47.0 \\
\hline Grand multiparty & 9 & 13.6 \\
\hline Number of abortions & & \\
\hline No abortion & 49 & 74.2 \\
\hline $1-2$ times & 10 & 15.2 \\
\hline Recurrent abortion & 7 & 10.6 \\
\hline
\end{tabular}

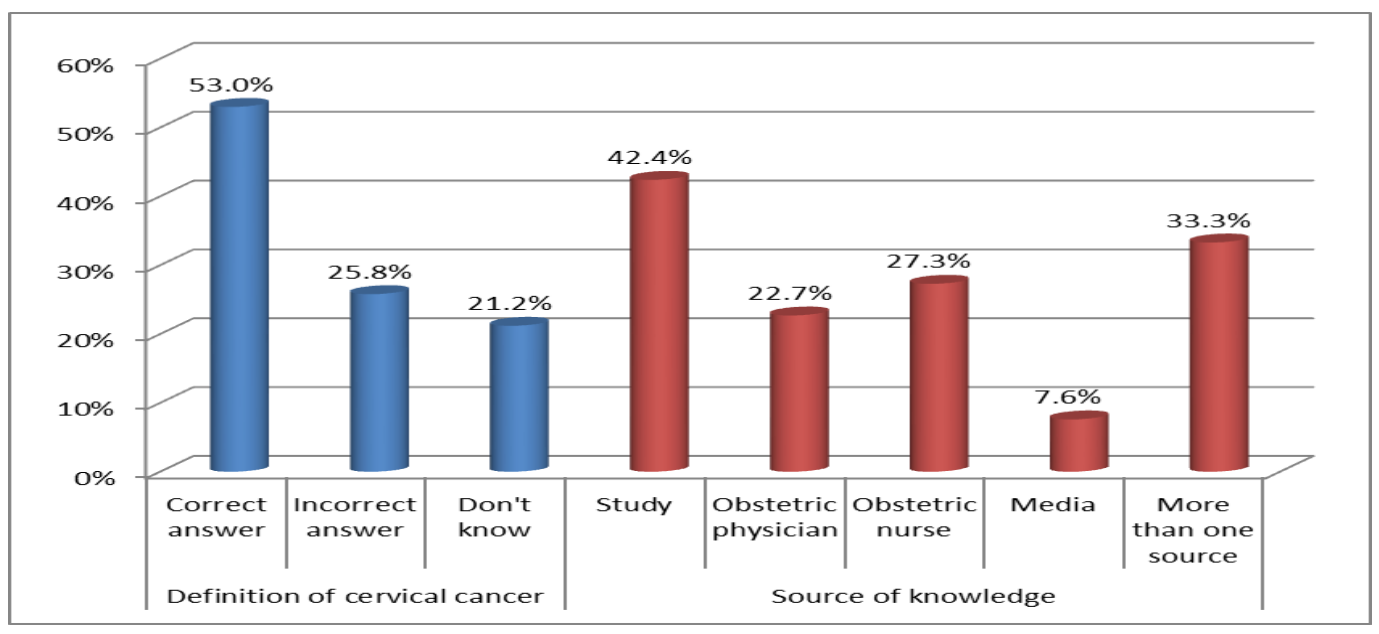

* More than one source of knowledge was checked.

Fig. 1: Distribution of the studied nurses according to their source of knowledge about cervical cancer

Table (3): Distribution of the studied nurses according to their knowledge about Pap smear.

\begin{tabular}{|l|c|c|}
\hline \multicolumn{2}{|c|}{ No.= 66 } & \multicolumn{2}{|c|}{ \% } \\
\hline First time do Pap smear & 14 & 21.2 \\
\hline After marriage & 16 & 24.2 \\
\hline At 30 year & 20 & 30.3 \\
\hline Previously cervical cancer & 10 & 15.2 \\
\hline After hysterectomy & 11 & 16.7 \\
\hline Don't know & \multicolumn{2}{|c|}{} \\
\hline Follow-up schedule & 28 & 42.4 \\
\hline Every year & 12 & 18.1 \\
\hline Every 3 year & 21 & 31.8 \\
\hline If negative for 3 times taken every 3 year & 16 & 24.2 \\
\hline Don't know & \multicolumn{2}{|c|}{} \\
\hline Who is responsible to take the smear & 39 & 59.1 \\
\hline Physician & 27 & 40.9 \\
\hline Nurse & \multicolumn{2}{|c|}{} \\
\hline Do you know the possible results & 27 & 40.9 \\
\hline Yes & 39 & 59.1 \\
\hline No & \multicolumn{2}{|l|}{} \\
\hline
\end{tabular}

* More than one answer allowed. 
Table (4) Distribution of the studied nurses according to their knowledge about cervical cancer.

\begin{tabular}{|l|c|c|}
\hline \multicolumn{2}{|c|}{ No.=66 } & \% \\
\hline Cervical cancer is sexually transmuted disease & \multicolumn{2}{|c|}{} \\
\hline Yes & 3 & 4.5 \\
\hline No & 49 & 74.2 \\
\hline Don't know & 14 & 21.2 \\
\hline
\end{tabular}

Table (5): Nurses' knowledge about risk factors of cervical cancer.

\begin{tabular}{|c|c|c|c|c|c|c|c|c|c|c|c|c|c|}
\hline & \multicolumn{6}{|c|}{ Pre test } & \multicolumn{6}{|c|}{ Post test } & \multirow{3}{*}{ P. value } \\
\hline & \multicolumn{2}{|c|}{ Yes } & \multicolumn{2}{|c|}{ No } & \multicolumn{2}{|c|}{ Don't know } & \multicolumn{2}{|c|}{ Yes } & \multicolumn{2}{|c|}{ No } & \multicolumn{2}{|c|}{ Don't know } & \\
\hline & No. & $\%$ & No & $\%$ & No & $\%$ & No & $\%$ & No & $\%$ & No & $\%$ & \\
\hline HPV infection & 16 & 24.2 & 38 & 57.6 & 12 & 18.2 & 49 & 74.2 & 15 & 22.7 & 2 & 3.0 & $<0.001 * *$ \\
\hline $\begin{array}{l}\text { Early marriage } \\
\text { less than } 18 \text { year }\end{array}$ & 11 & 16.7 & 44 & 66.7 & 11 & 16.7 & 43 & 65.2 & 22 & 33.3 & 1 & 1.5 & $<0.001 * *$ \\
\hline $\begin{array}{l}\text { Sex with multiple } \\
\text { partners }\end{array}$ & 2 & 3.0 & 53 & 80.3 & 11 & 16.7 & 19 & 28.8 & 45 & 68.2 & 2 & 3.0 & $<0.001 * *$ \\
\hline Multi parity & 8 & 12.1 & 48 & 72.7 & 10 & 15.2 & 39 & 59.1 & 24 & 36.4 & 3 & 4.5 & $<0.001 * *$ \\
\hline $\begin{array}{l}\text { Low social } \\
\text { economic status }\end{array}$ & 2 & 3.0 & 54 & 81.8 & 10 & 15.2 & 23 & 34.8 & 39 & 59.1 & 4 & 6.1 & $<0.001 * *$ \\
\hline Hereditary & 4 & 6.1 & 52 & 78.8 & 10 & 15.2 & 19 & 28.8 & 44 & 66.7 & 3 & 4.5 & $0.001 * *$ \\
\hline
\end{tabular}

Table (6): Nurses' knowledge about cervical cancer signs and symptoms.

\begin{tabular}{|c|c|c|c|c|c|c|c|c|c|c|c|c|c|}
\hline & \multicolumn{6}{|c|}{ Pre-test } & \multicolumn{6}{|c|}{ Post-test } & \multirow{3}{*}{ P. value } \\
\hline & \multicolumn{2}{|c|}{ Yes } & \multicolumn{2}{|c|}{ No } & \multicolumn{2}{|c|}{$\begin{array}{l}\text { Don't } \\
\text { know }\end{array}$} & \multicolumn{2}{|c|}{ Yes } & \multicolumn{2}{|c|}{ No } & \multicolumn{2}{|c|}{$\begin{array}{l}\text { Don't } \\
\text { know }\end{array}$} & \\
\hline & No. & $\%$ & No. & $\%$ & No. & $\%$ & No. & $\%$ & No. & $\%$ & No. & $\%$ & \\
\hline Post coital bleeding & 4 & 6.1 & 47 & 71.2 & 15 & 22.7 & 43 & 65.2 & 19 & 28.8 & 4 & 6.1 & $<0.001 * *$ \\
\hline $\begin{array}{l}\text { Inter menstrual } \\
\text { bleeding }\end{array}$ & 14 & 21.2 & 37 & 56.1 & 15 & 22.7 & 44 & 66.7 & 19 & 28.8 & 3 & 4.5 & $<0.001 * *$ \\
\hline Vaginal discharge & 7 & 10.6 & 44 & 66.7 & 15 & 22.7 & 40 & 60.6 & 22 & 33.3 & 4 & 6.1 & $<0.001 * *$ \\
\hline $\begin{array}{l}\text { Blood stained with } \\
\text { vaginal discharge }\end{array}$ & 24 & 36.4 & 28 & 42.4 & 14 & 21.2 & 39 & 59.1 & 20 & 30.3 & 7 & 10.6 & $0.027 *$ \\
\hline Pain in pelvic reign & 18 & 27.3 & 34 & 51.5 & 14 & 21.2 & 36 & 54.5 & 23 & 34.8 & 7 & 10.6 & $0.005^{* *}$ \\
\hline Pain during inter course & 17 & 25.8 & 34 & 51.5 & 15 & 22.7 & 23 & 34.8 & 37 & 56.1 & 6 & 9.1 & 0.087 \\
\hline
\end{tabular}

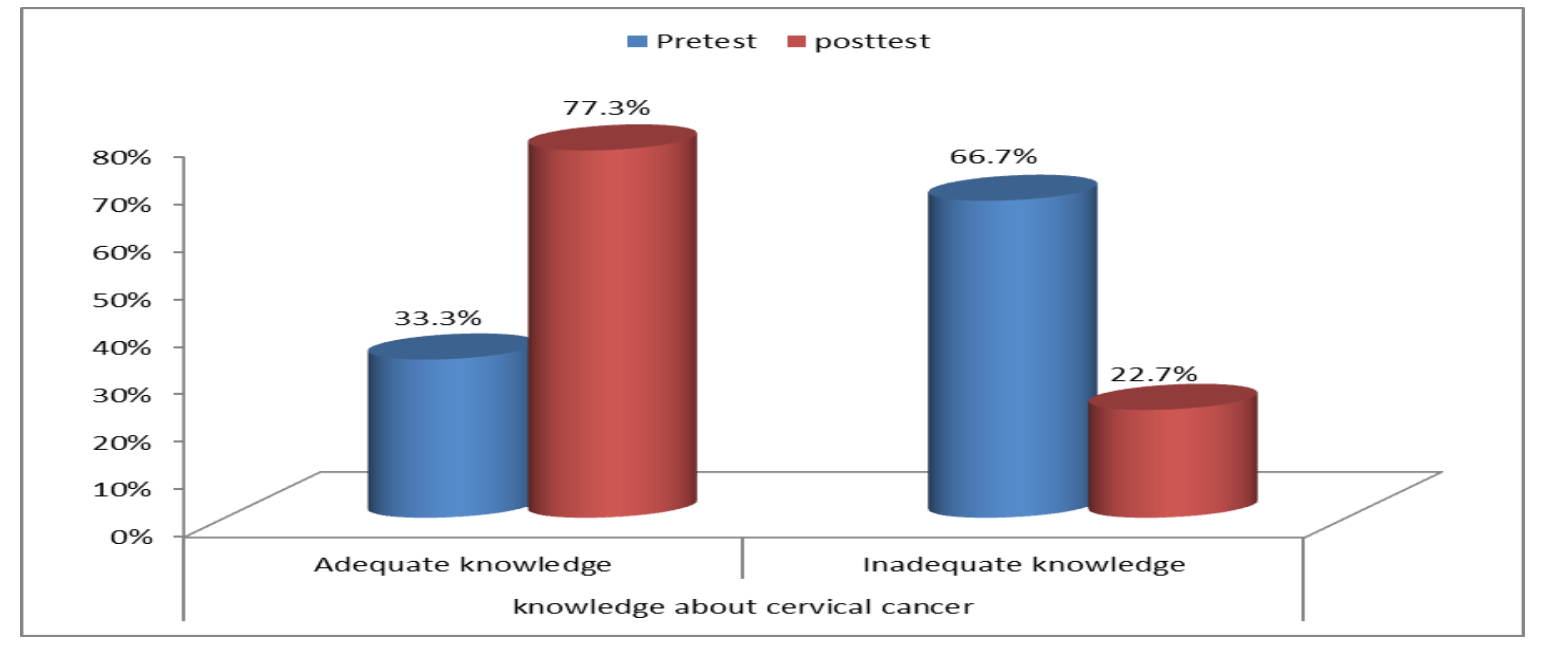

Fig (2): Total nurses knowledge about cervical cancer 
Table (7) Distribution of the studied nurses according to their attitude toward Pap smear.

\begin{tabular}{|l|c|c|}
\hline \multicolumn{2}{|l|}{ No.= 66 } & \% \\
\hline Pap test helps for early detection of cancer & \multicolumn{2}{|c|}{} \\
\hline Strongly agree & 59 & 89.4 \\
\hline Agree & 6 & 9.1 \\
\hline Disagree & 1 & 1.5 \\
\hline Pap test helps in decrease maternal morbidity and mortality & \multicolumn{2}{|c|}{} \\
\hline 1) Strongly agree & 52 & 78.8 \\
\hline 2) Agree & 12 & 18.2 \\
\hline 3) Not agree & 2 & 3.0 \\
\hline Do you discuss Pap smear with your family or friends before? & \multicolumn{2}{|c|}{} \\
\hline Yes & 16 & 24.2 \\
\hline No & 50 & 75.8 \\
\hline Do you believe that your job help in cancer prevention & \multicolumn{2}{|c|}{} \\
\hline 1$) \quad$ Strongly agree & 47 & 71.2 \\
\hline Agree & 19 & 28.8 \\
\hline 3) Not agree & \multicolumn{2}{|c|}{} \\
\hline
\end{tabular}

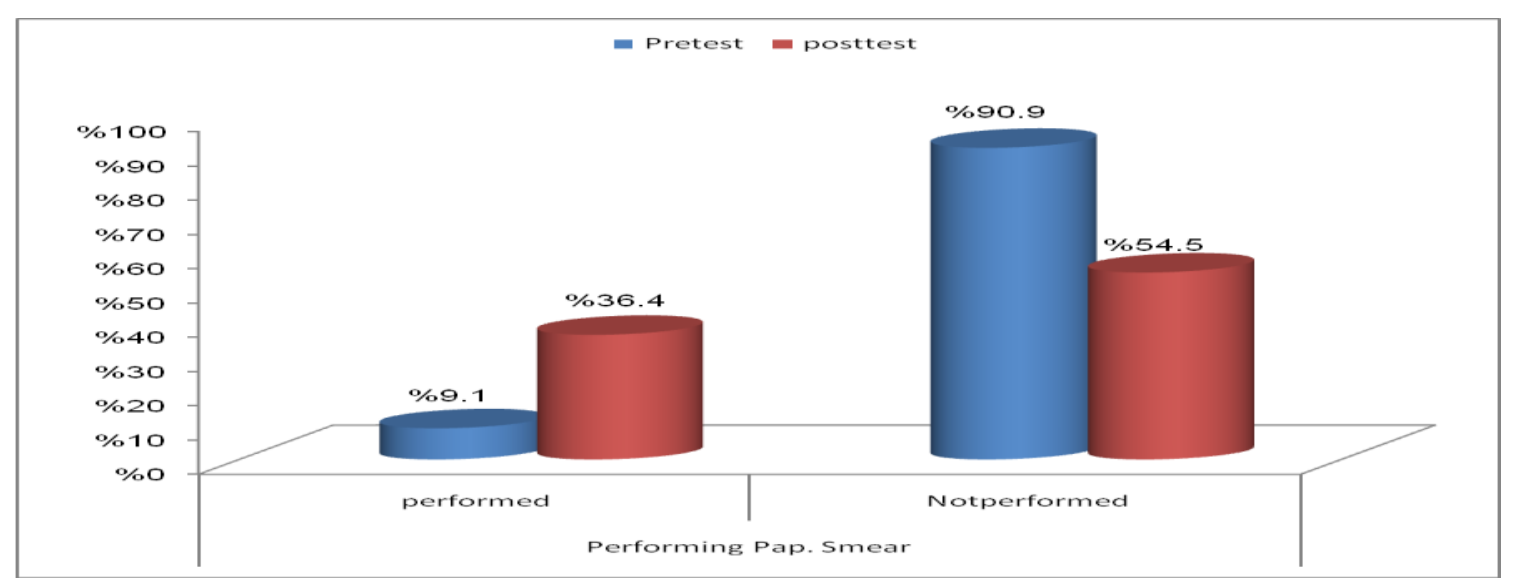

Fig (3): Number of nurses who perform Pap. Smear

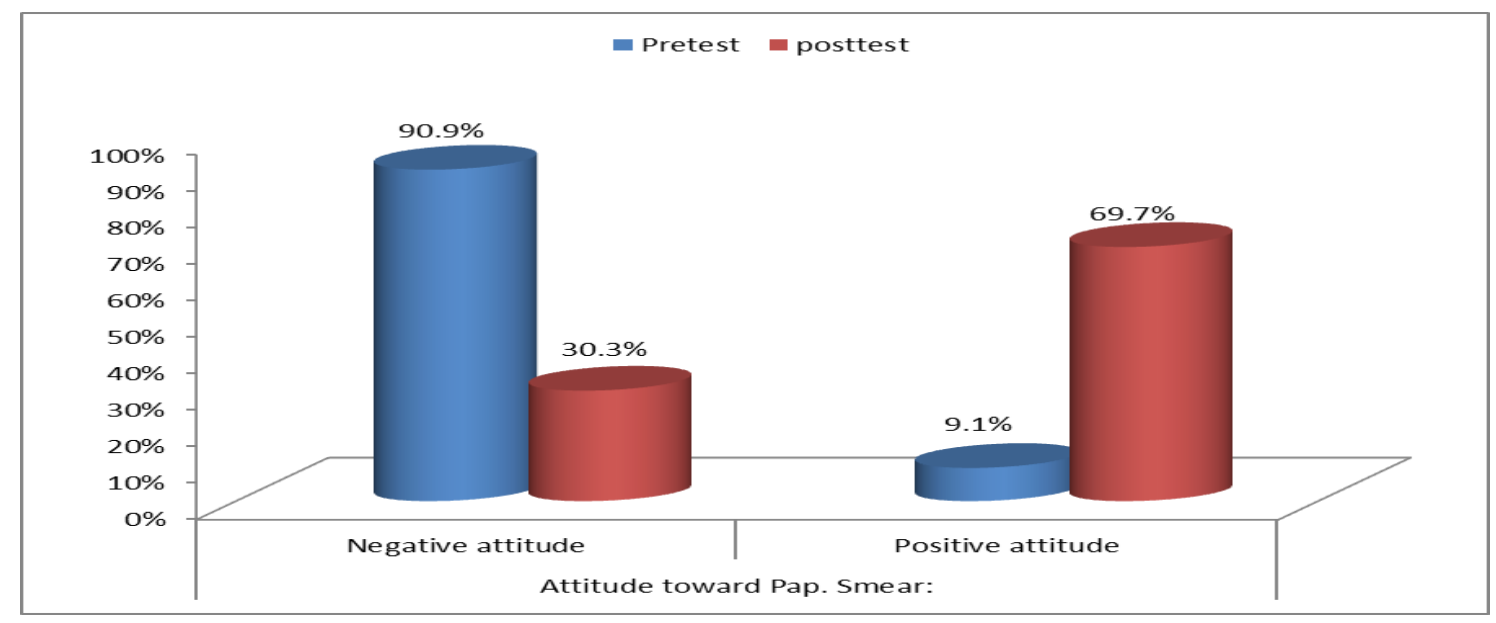

Fig. (4): Nurses attitude toward Pap. Smear 


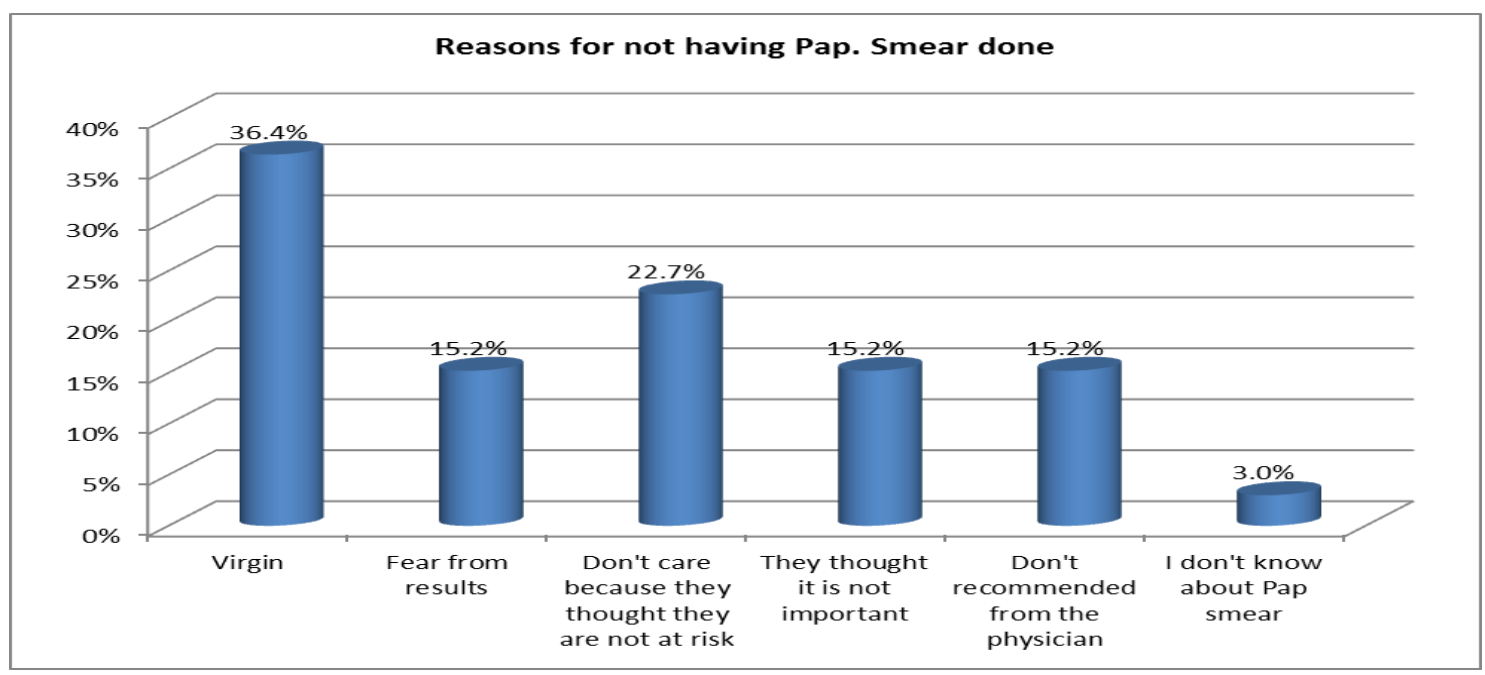

* More than one answer allowed.

* Fig 5: Distribution of the studied nurses according to reasons for not having a Pap. Smear

Table (8): Multiple regression analysis between sociodemgraphic data and level of knowledge about cervical cancer.

\begin{tabular}{|l|c|c|c|}
\hline & Beta & T & Sig. \\
\hline Age & -0.087 & -0.123 & 0.902 \\
\hline Residence & 0.042 & 0.314 & 0.754 \\
\hline Marital status & 0.221 & 0.358 & 0.722 \\
\hline Age at marriage & -0.196 & -0.345 & 0.731 \\
\hline Duration of marriage & 0.009 & 0.023 & 0.981 \\
\hline Scientific description & -0.073 & -0.494 & 0.623 \\
\hline Duration of work & 0.199 & 0.312 & 0.756 \\
\hline Place of work & 0.198 & 1.462 & 0.150 \\
\hline Number of pregnancies & -0.071 & -0.255 & 0.800 \\
\hline Number of Abortions & 0.218 & 1.341 & 0.186 \\
\hline
\end{tabular}

Table (9): Multiply regression analysis between sociodemgraphic data and attitude toward Pap. Smear.

\begin{tabular}{|l|c|c|c|}
\hline & Beta & T & P. value \\
\hline Age & 0.010 & 0.018 & 0.986 \\
\hline Residence & -0.106 & -0.963 & 0.340 \\
\hline Marital state & 0.489 & 0.975 & 0.334 \\
\hline Age at marriage & -0.160 & -0.347 & 0.730 \\
\hline Duration of marriage & -0.487 & -1.528 & 0.132 \\
\hline Scientific description & 0.071 & 0.589 & 0.558 \\
\hline Duration of work & -0.160 & -0.308 & 0.759 \\
\hline Place of work & 0.361 & 3.278 & $0.002^{* *}$ \\
\hline Number of pregnancies & -0.053 & -0.233 & 0.816 \\
\hline Number of Abortions & 0.240 & 1.814 & 0.075 \\
\hline
\end{tabular}

Table (1): shows that about half (57.6\%) Of nurses were at age range between 20 to 25 years and most of them $(66.7 \%)$ live in urban areas. As regards to marital status, most of nurses $(65,2 \%)$ were married, $59 \%$ of them had diploma degree and $24.2 \%$ graduated from technical institute of nursing, while only $16.7 \%$ had bachelor degrees. Most of nurses $(68.2 \%)$ working at in patient departments, and according to duration of experience $37.9 \%$ of them had less than 5 years of experience and $34.8 \%$ of them had an experience of more than 10 years. 
Table (2): shows that about half of nurses (47\%) had at least one child, while only $13.6 \%$ of them had more than 5 children. Regarding history of abortion, majority of them (74.2\%) were not previously aborted.

Fig (1): Represents knowledge about cervical cancer $53 \%$ of nurses knew the definition of cervical cancer while $47 \%$ of them don't know the definition or define it with wrong definition.. The most common source of knowledge for them was there study $(42.4 \%)$, followed by obstetrical nurse $(27.3 \%)$ and obstetrical physician $(22.7 \%$, only $7.6 \%$ of nurses acquire their knowledge from media.

Table (3): Concerning nurses' knowledge and attitude it can be observed from that $21.2 \%$ of the nurses knew that the first time for perform Pap. Smear is after marriage (first intercourse), as regards to frequencies of test, $42.4 \%$ of the studied nurses knew that the frequency of test done every year, and $31.8 \%$ of them knew that the test repeated every 3 years if it was negative for 3 times, while $24.2 \%$ of them didn't know the follow up schedule of Pap smear test.

Table (4): The majority of nurses (74.2\%) perceived cervical cancer as not a sexually transmitted disease and $21.3 \%$ of them didn't know wither cervical cancer is a sexually transmitted disease or not.

Table (5): This table illustrated the pretest- posttest women's knowledge about cervical cancer risk factors among nurses, the most common known risk factor was HPV infection $24.2 \%$ and $74.2 \%$ respectively, it was observed statistical significant differences between nurses knowledge as regard cervical risk factors between pr and posttest results.

Table (6): This table demonstrates the nurse's perception as regard sign and symptoms of cervical cancer for pre and post test results. It was observed that the most common known sign and symptoms was the blood stained with vaginal discharge $36.4 \%$ among pretest results while it was intermenstrual bleeding $66.7 \%$ for post test results, with statistical significant differences.

Fig. (2): It was observed from this table the improvement in nurse's knowledge about cervical cancer, only 33,3\%.of nurses had adequate knowledge for the pretest evaluation in comparison to $77.3 \%$ of them in post-test evaluation, and $22.7 \%$ of them still had inadequate knowledge about cervical cancer in post-test assessment, with highly statistical significant differences.

Table (7) It was observed from this table that more than half of nurses $(54.1 \%)$ perceived that the physician is the person who is responsible to take Pap. smear.,.89.4\% of nurses agree that Pap test could help in early detection of cervical cancer and
$78.8 \%$ of them agree it can decrease women's morbidity and mortality.

Fig (3): This figure illustrated the effect of the program on nurses performing Pap. Test for herself, the number of nurses who were perform Pap.test increased after program implementation it is increased from $9.09 \%$ to $36.36 \%$ respectively.

Fig (4): In this figure, researcher observed nurses' attitude toward Pap. Smear. It was observed that the majority of them $(90.9 \%)$ had a negative attitude toward pap. Smear and only $9.1 \%$ of them had a positive attitude in pretest evaluation. In post-test assessment, it was observed that $69,7 \%$ of nurses had a positive attitude toward pap. Smear and $30.3 \%$ of them stile had a negative attitude, with highly statistical significant differences.

Fig (5): This figure represent causes of not having a Pap., test the most common causes for that, they reported that they are not at a risk for cervical cancer $(27.7 \%)$ and $15.2 \%$ of them didn't had a test because they don't hear about it

Table (8): This table shows the multiple regression analysis between sociodemographic data and level of knowledge about cervical cancer. It was observed that place of work was the most variable which affect the nurses' knowledge about cervical cancer.

Table (9): This table shows the multiple regression analysis between sociodemographic data and nurses' attitude toward Pap. Smear. It was observed that the place of work was the most variable that affect the nurse's attitude toward cervical cancer screening (Pap. Smear), followed by number of abortions and marital status.

\section{Discussion}

Knowledge is an essential first step in the development of attitude. Although knowledge is considered to be a precursor of attitude ( Shekhar et al., 2013)

Cervical cancer and its mortality have been proven preventable by various screening and treatment strategies aimed at sexually active women. Developed countries have demonstrated significant reduction in cervical cancer mortality through their extensive organized population based on cervical cancer screening programs ( Shekhar et al., 2013).

Pap smear test is one of the most screening tools for the early diagnosis of cervical cancer; the rate of women having Pap testing is equal or above $80 \%$ in developed countries \& varies between 46 to $68 \%$ in developing countries (Ertem, 2009). WHO recommends that cervical cancer screening programs should start screening women aged 30 years or more and should occur at three-year intervals (Sudenga et al., 2013) 
This study was conducted for the purpose of assess the effect of educational program about cervical cancer prevention on nurse's awareness about cervical cancer \& Pap smear practices.

66 nurse were included in this study with mean age $29.3 \pm 9.6$, this study data reflect that more than two third of the subject were from urban area and were married $(66.7 \%$ \& $65.2 \%)$ respectively.

According to scientific qualification of nurses, it was observed that more than half of them had a diploma degree, and only $16.7 \%$ had a bachelor degree in nursing, the main duration of work were 10.0 \pm 9.6 years.

It was established in this study that about two-thirds of them had at least one pregnancy and most of them not previously aborted.

Through conducting the present study program, researcher present answer to the given hypothesis, nurse's knowledge was improved after implementing the educational program about cervical cancer and the screening test and attitude also was changed to be appositive attitude. In farther confirmation of this foregoing interpretation, the present study reported that nurses being a wear of the benefits of cervical cancer screening test, as 24 (36.36\%) nurse undergoing cervical screening test (Pap. Smear) for their won.

This study reflects that the nurses had inadequate knowledge about the first time to take Pap smear, only one-fifth of them reported that the first time for the Pap smear to take place after practicing intercourse. And majority of them didn't know its follow-up schedule. Most of nurses know that Pap smear is a cervical cancer screening tool and also they are aware that this test helps in early detection of precancerous lesions but didn't know that women should begin to take pap smear at proximally 3 years after the first intercourse and if the reported test were normal, It should be done every 3 years.

Hadi \& Azimirad (2010), who were studied the knowledge attitude and practice of women in Shiraz about Cervical Cancer and Pap Smear reported that (36.9\%)of the sample did not know the correct time of Pap smear, which is very near to our results. Yakout et al.,(2016), who were studied Knowledge and Beliefs of Egyptian women about cervical cancer and screening test, reported that the major findings of their study showed that $88.7 \%$ of the respondents were not known of the cervical screening (Pap smear), which is disagree with our finding and that is due to the differences in the sample characteristics.

This finding agree with Goyal et al., (2013), they find that Pap smear was recognized as major screening technique by $74 \%$ of the studied nurses.

Al-Meer et al., (2011), also reported that (39.4\%) of the sample had had a Pap smear at least once in their life. This may be due to the difference in the sample size and in contrast with the sample culture that they see in our country the investigation done only for sick people. This also agree with Ertem (2009), he reported that the results of his study indicated that most of the nurses knew that pap smear test as a cervical cancer screening methods, should be done yearly, but did not know that women should begin cervical cancer screening at approximately 3 years after the first sexual life and if the repeated pap smear tests were normal, it could be done every 2-3 years. Most of the nurses knew that Pap smear test decreased mortality of cervical cancer.

Apart from inadequate knowledge, it is well known that the most frequently reported reasons for not having a recent Pap smear were belief that it might be painful, followed by embarrassment, not being referred by a health professional, and fear of having positive results (Al-Meer et al., 2011). In the present study, the most reported reason for not having Pap smear was don't care because they thought they are not at risk, followed by fear from results. These results were disagree with Goyal et al., (2013), they reported that the most common reason for not had Pap smear test was Not thought about it, No time and Still young for it respectively. The discrepancies between the present study finding and the previous one might be attributed to differences in the level of education and socioeconomic factors between the two studies population.

The most common reasons for avoiding a Pap smear test which detected by Thippeveeranna et al., (2013) were lack of any symptoms lack of counseling physician does not request and fear of vaginal examination, which partially agree with our reported reason in this study. This finding reported in their study which conducted in a Tertiary Hospital in North Eastern India to assess Knowledge, Attitude, and Practice of the Pap smear as a Screening Procedure among Nurses.

On the other line of the present study Yakout et al., (2016) reported that the most frequently perceived cultural barriers to obtaining Pap tests were being uncomfortable with having a test performed by a male doctor but prefer female doctor, disagree not needing a test when feeling well, believing a test will be painful or unpleasant, and believing a Pap test is embarrassing.

The belief that it is unnecessary to have a Pap test when one feels well is consistent with cultural beliefs that healthcare is a service that one seeks for specific, manifested complaints and symptoms

This study revealed improvement in nurse's knowledge toward cervical cancer, only one-third of nurses had adequate knowledge for the pretest evaluation in compeer to two-thirds of them in post- 
test evaluation than one third of them still haven't knowledge about cervical cancer in post test assessment. This result was congruent with (EL Sharkawy et al., 2014), they reported in their study which conducted to assess the effect of nursing educational Guidelines on Women's Awareness, Health Practices and Beliefs Regarding prevention and early detection of breast and cervical cancer in Cairo city, the results of their study revealed that the knowledge before the guidelines implementation was generally unsatisfactory. Positive highly statistically significant improvements in all areas of knowledge regarding cervical cancer were revealed post guidelines implementation, similar finding reported by Fouda \& Elkazeh (2013) in their study which conducted to assess The Impact of an Educational Intervention on Women's Knowledge and Perception Regarding Cervical Cancer and Human Papillomavirus Vaccines in Tanta City they reported a significant increase in knowledge on cancer cervix, Pap smear

This finding also agree with Sichanh et al., (2014), they reported that The first result of their study was that the general level of knowledge about cervical cancer of the interviewed women was very poor, in the same line the finding agree with Ertem (2009 \& Thippeveeranna et al., (2013), they reported that The majority of the nurses in their study had inadequate knowledge about causes and risks factors of cervical cancer.

For the nurse's attitude toward Pap. smear. It was observed that the majority of nurses had a negative attitude toward Pap smear in pretest evaluation. In post-test assessment, it was observed that more than two-thirds of nurses had a positive attitude toward pap. Smear. This result can pint to the most important point in this study that when nurses knowledge improved they may act an alarm to induce themselves to perform screening test for their won.

This study demonstrated that the nurses having knowledge about cervical cancer risk factors such as multiparty, HPV and hereditary factor, this show a significant relation between nurses level of knowledge in pre and post test about different risk factors.

This disagree with Sudenga et al., (2013) they reported that the most common known risk factors defined in their study were, multiple sex partners, vaginal bleeding, followed by smoking and having sexually transmitted diseases.

A previous study in Uganda found that less than $40 \%$ of medical workers understood risk factors for cervical cancer. This referred to the differences in cultures and beliefs in our country that it doesn't allow multiply sexual relations.
In the current study the nurses were a wear about different symptoms of cervical cancer, the most common known sign and symptoms was the blood stained with vaginal discharge among pretest results while the most known symptoms was inter-menstrual bleeding for post test results, with statistical significant differences, other studies showed similar results Abdul-Aziz (2012) reported in her study that most of the females have knowledge about the clinical picture of cervical cancer. The most widely identified symptom was the vaginal bleeding followed by Pelvic pain and disturbance of menstruation, which is similar to our finding.

According to multiple regression analysis between socodemographic data and level of knowledge about cervical cancer. It was observed that the number of abortions and place of work were the most variables which affect the nurses knowledge about cervical cancer.

Sichanh et al., (2014) disagree with this finding, they reported in the study which conducted to assess Knowledge, awareness and attitudes about cervical cancer among women attending or not an HIV treatment center in Lao PDR the most five variables were independently found associated with a score of knowledge upon cervical cancer higher than other variables were, occupation, province, education level, matrimonial status and HIV status.

In our study, it was observed that the place of work was the most variable that affect the nurse's attitude toward cervical cancer screening (Pap. Smear), followed by number of abortions and marital status. Finally, it is encouraging to find out in the present results, that there was an improvement in nurse's knowledge and change in their attitude, as nurses represents an important health care giver and that may be reflected on their services which they provide in the hospital and their communities to encourage doing screening test.

\section{Conclusion}

Nurses had adequate knowledge about cervical cancer screening after implementing the educational program and their attitude was changed positively toward screening themselves.

\section{Recommendations}

- Hospital should periodically organize seminars and training for health personnel especially nurses which form a group of professionals that can give health education to women about cervical cancer.

- Improve nurses and all women's awareness about cervical cancer screening test through continuous refreshment tanning program for nurses and mass media to the general population. 


\section{Limitation of the study}

Absence of some nurses and refuse of others were the main problem the researchers faced during this study because it's effect on the study sample.

\section{References}

1. Abdul-Aziz M., (2012): Knowledge, Attitude and Practice towards Cervical Cancer among Reproductive Health Clients at the University of Science \& Technology Hospital-Sana'a in Yemen. YEMENI JOURNAL FOR MEDICAL SCIENCES (6): 21-27.

2. Adenike O., Akhigbe, \& Vivian O., (2010): Knowledge, attitudes, and practice of breast cancer screening among female health workers in a Nigerian urban city. BMC Cancer 2009. 9:203.

3. Al-Meer F., Aseel M., Al-Khalaf J., AlKuwari M., \& Ismail M., (2011): Knowledge, attitude, and practices regarding cervical cancer and screening among women visiting primary health care in Qatar. Eastern Mediterranean Health Journal. 17(11).

4. Al-Shaikh K., Almussaed E., \& Fayed A., et al., (2014): Knowledge of Saudi female university students regarding cervical cancer and acceptance of the human papilloma virus vaccine. Saudi Med Journal.35 (10): 12231230.

5. A Qalawa S., Mohamed M., \& Eltayb R., (2013): Cancer Awareness among Non-medical University Students in Sudan. International Journal of Advanced Research; 1, (8): 93-110.

6. Arulogun O., \& Maxwell O., (2012): Perception and utilization of cervical cancer screening services among female nurses in University College Hospital, Ibadan, Nigeria. The Pan African Medical Journal. 11:69.

7. Armstrong C., (2007): ACIP Releases Recommendations on Quadrivalent Human Papillomavirus Vaccine. Am Fam Physician. 75 (9):1391-1380.

8. Dabash R., Vajpayee J., Jacob M., Prasad L., (2015): A strategic assessment of cervical cancer prevention and treatment services in 3 districts of Uttar Pradesh, India. Reproductive Health.11(10).

9. EL Sharkawy A., Hassan M., \& Abd ElSattar R., (2014): Effect of Nursing Educational Guidelines on Women's Awareness, Health Practices and Beliefs Regarding Prevention and Early Detection of Breast and Cervical Cancer. Life Science Journal 11(6):707- 724.
10. Ertem G., \& Kocer A., (2009): Breast selfexamination among nurses and midwives in Odemis health district in Turkey. Indian $\mathbf{J}$ Cancer. 46:208-13.

11. Ferlay J., Bray F., Pisani P., \& Parkin D., (2004): Cancer Incidence, Mortality and Prevalence Worldwide. In IARC Cancer Base No. 5, version 2.0. IARC Press, Lyon; 2004.

12. Fouda L ., \& Elkazeh E., (2013): The Impact of an Educational Intervention on Women's Knowledge and Perception Regarding Cervical Cancer and Human Papillomavirus Vaccines in Tanta City: Applying Health Belief Model. Life Science Journal;10(12s)

13. Gan D., \& Dahlui M., (2013): Cervical screening uptake and its predictors among rural women in Malaysia. Singapore Med J. 54(3): 163-168.

14. Goyal A., Vaishnav G., Shrivastava A., et., al., (2013): knowledge, attitude \& practices about cervical cancer and screening among nursing staff in a teaching hospital. International Journal of Medical Science and Public Health. 2 Issue 2.

15. Gul Ertem G., (2009): Awareness of Cervical Cancer Risk Factors and Screening Behaviour among Nurses in a Rural Region of Turkey. Asian Pacific J Cancer Prev, 10: 735-738.

16. Hadi N., \& Azimirad A., (2010): Knowledge Attitude and Practice of Women in Shiraz about Cervical Cancer and Pap Smear 2009. Iran J Cancer. 3:117-26.

17. Jefferies, H., (2008): Cervical cancer: an overview of screening and diagnosis. Nursing Times. 104( 44): 26-27.

18. Kahn J., (2009): HPV vaccination for the prevention of cervical intraepithelial neoplasia. N Engl J Med. Jul 16;361(3):271-8.

19. Mutyaba T., Mmiro F., \& Weiderpass(2006): Knowledge, attitudes, and practices on cervical cancer screening among the medical workers of Mulago Hospital, Uganda. BMC Medical Education. 6(13).

20. Nganwai P., et al., (2007): Knowledge, Attitudes, and Practices vis-à-vis Cervical Cancer Among Registered Nurses at the Faculty of Medicine, Khon Kaen University, Thailand. Asian Pacific J Cancer Prev. 9: 15-18

21. Nwankwo C., Aniebue U., Aguwa N., et al., (2010): Knowledge attitudes and practices of cervical cancer screening among urban and rural Nigerian women: a call for education and mass screening. European Journal of cancer care May.

22. Sandy J., (2010): Knowledge of Selected Nurses and Clinical Instructors Towards Pap 
Smear In Relation To Cervical Cancer. Partial Fulfillment of the Requirements for Master in Nursing Submitted to The Faculty of Graduate Studies.

23. Shekhar S., Chanderdeep S., Sita T., \& Nidhi R., (2013): Cervical Cancer Screening: Knowledge, Attitude, and Practices among Nursing Staff in a Tertiary Level Teaching Institution of Rural India, Asian Pacific Journal of Cancer Prevention, 14.

24. Sichanh C., \& Chanthavilay p., (2014): Knowledge, awareness, and attitudes about cervical cancer among women attending or not an HIV treatment center in Lao PDR. BMC Cancer .14 :161-169.

25. Sudenga S., Rositch A., Otieno W., et al., (2013): Brief Report: Knowledge, attitudes, practices and perceived risk of cervical cancer among Kenyan women. Int J Gynecol Cancer. 23(5): 895-899.

26. Thippeveeranna C., Mohan1 S., Singh L., et al., (2013): Knowledge, Attitude and Practice of the Pap Smear as a Screening Procedure Among Nurses in a Tertiary Hospital in North Eastern India. Asian Pacific Journal of Cancer Prevention,14: 849-852.

27. WHO,(2004): Planning and Implementing Cervical Cancer Prevention and Control Programs. A Manual for Managers.

28. Yakout S., Moawed S., \& Gemeay S., (2016): Cervical Cancer and Screening Test (PAP Test): Knowledge and Beliefs of Egyptian Women. American Journal of Nursing Science. 5(5): 175-184. 